\title{
Ultrasonic dyeing of wool fabric with aqueous extract of Ratanjot (Onosma echioides) natural dye
}

\author{
Devi, O.R. ${ }^{1}$ 凶, Bains, S. $^{2}$, Grewal, S. $^{3}$
}

\begin{abstract}
The purpose of this study is to compare the conventional and ultrasonic dyeing methods in terms of its colour strength and colour fastness properties of wool fabric dyed with Ratanjot root. The results suggested that dyeing of wool fabric with natural dye Ratanjot (Onosma echioides) using ultrasonic waves, significantly improved the dye uptake percentage to 12.31 per cent from conventional heating methods. The fastness grade were found to be higher with ultrasonic than conventional heating. Additionally, the fabric dyed using ultrasonic waves gave a deeper shade and good colour intensity even at lower dyeing time $(75 \mathrm{~min})$ and temperature $\left(60^{\circ} \mathrm{C}\right)$. Therefore, ultrasound wave represents a promising technique for increasing diffusion of dye by the effect of cavitation, as well as for improving the effectiveness of processes when compared to conventional heating.
\end{abstract}

Key words: Conventional, Colour Strength, Colour fastness, Ratanjot, Ultrasonic

\section{Introduction}

Natural dyes are colourants obtained from natural resources such as plants, minerals and animals. The dyeing of natural colourants was considered as one of oldest techniques, practiced by ancient people before thousands of years (Prabhu and Bhute, 2012). The ancient arts namely Ajanta, Ellora, Sithannavasal, Mithila wall paintings (mural art) and Egyptian pyramids were done with natural colourants (Mukherjee and Kanakarajan, 2017). Besides, Vedas also cited red, yellow, blue, black and white as main dyeing colours and stated that, the ancient craftsmen dyed blue from indigo, yellow from turmeric and saffron, brown from cutch and red from lac, safflower and madder. But later, synthetic dye was introduced in the dye market considerably due to its cheaper cost, wide range of colours and good fastness properties (Paisan et al., 2002; Saravanan and Chandramohan, 2011). However, during the last few decades, the use of synthetic dyes is gradually decreasing due to increase environmental awareness and harmful effects because of either toxicity or their nonbiodegradable nature. In addition to above, some serious health hazards like allergy and carcinogenicity are associated with the synthetic

\section{Author's Address}

Department of Apparel and Textile Science, Punjab Agricultural University, Ludhiana, Punjab, India-141004 E-mail.: oinam.roselyn@gmail.com dyes. As a result, recently a ban has been enforced all over the world including European Economic Community (EEC), Germany, USA and India on the use of some synthetic dyes (Yusuf et al., 2017). Therefore, natural dye started regaining interest in textile industries for its biodegradable, non-toxic and environment friendly nature (Yusuf et al., 2016). The name Ratanjot (Onosma echoides) is attributed to the roots of various Boraginaceous plant species. Traditionally, it is used as a food colourant in cosmetic formulations and pharmaceutical preparations. Several naphthoquinone pigments are present in the bark of ratanjot roots, which give a violet red colour. The main pigment present in ratanjot root is alkanin (Fig.1). It is regarded as one of the important herbal drugs of indigenous systems of medicine. The root bark of ratanjot is reported to have several biological properties such as antibacterial, antifungal, antiviral, antioxidant, radical scavenging and antithrombotic activity (Arora et al., 2009). Previously, many researchers reported ratanjot as one of the potential natural dyes sources (Gupta and Saini, 2018; Chattopadhyaya et al., 2018; Chattopadhyaya et al., 2013). Traditionally, conventional boiling method is used for the dyeing textiles with natural dyes; however, there are certain limitations such as poor colour strength, 


\section{Devi et al.}

complexity of dyeing process, longer time for dye extraction, poor colour fastness and reproducibility of shades. Thus, it is necessary to explore a suitable alternative technique for more efficient natural dyeing to improve the dyeing properties of natural dyes (Rahman et al., 2013). In this study, ultrasonic cleaner approach was used as suitable method for dyeing. Ultrasound dyeing method saves energy by dyeing at lower temperature or shortens the process, lowers the consumption of auxiliary chemical, lesser processing costs, which lead to increase in the competiveness in the industry, process improvement by controlling the colour shade (Parvinzadeh et al., 2009). The ultrasonic dyeing mechanism involves formation of cavitation, compression or rarefraction and streaming as shown in Fig.2. Due to cavitation (the phenomenon of collapse and expansion of micro bubbles in the liquid medium), ultrasound improves dyeing process and cavitation process give enhancement in four ways - (i) breaking-up aggregates of dye in solution which would increase their rate of diffusion into the fibre, (ii) removing air from between fibres to improve fibre-liquid contact, (iii) disrupting the fibre-liquid boundary layer to increase the rate of dye diffusion into the fibre and (iv) increasing the swelling of fibres which would increase the rate of dye diffusion through the fibre and increase in the area of the fibre-liquid interface. Besides, the pollution parameters such as BOD (Biochemical Oxygen Demand), COD (Chemical Oxygen Demand) and TOC (Total Organic Carbon) levels in textile dye house effluents are found to be decreased after using ultrasonic dyeing method. The dyeing processes on cotton, wool, silk, acrylic, nylon and polyester with the use of ultrasound energy have dye diffusion coefficient of 30 per cent and reduces the dyeing time by 20 per cent (Udrescu et al., 2014). A lot of work has been carried out for dyeing of textiles with natural dye using conventional heating but the work on ultrasonic technique is very limited. One study reported that ultrasound approach improved dyeability as well as colour fastness properties of dyed fabric (Kamel et al., 2011). Similarly another study also reported that the use of ultrasound wave improved the dye uptake with lower temperature, i.e, $60^{\circ} \mathrm{C}$ (Mansour and Haffernan, 2011). Therefore, in the present study, wool fabric was dyed with aqueous extract of ratanjot dye using both conventional and ultrasonic dyeing methods and compared it in terms of its colour strength, CIE Lab values and colour fastness properties.<smiles>CC(C)=CC[C@@H](O)C1=CC(=O)c2c(O)ccc(O)c2C1=O</smiles>

Figure 1: Alkanin: the main colour component.
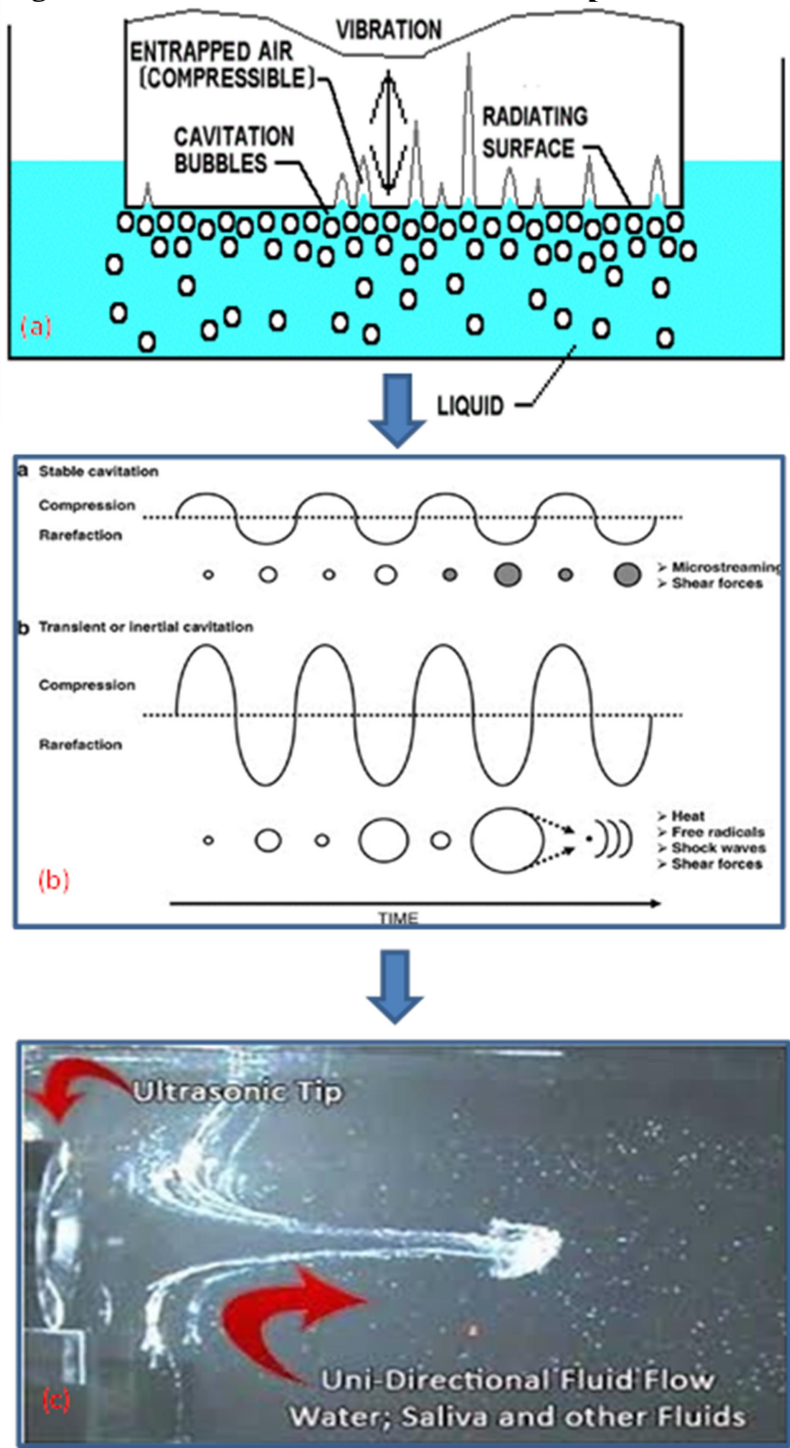

Figure 2: Schematic diagram of ultrasonic dyeing mechanism: (a) Cavitations or bubbles formed in liquid by ultrasonic waves (b) Forces created during compression or rarefaction (c) Rapid movement of liquids by ultrasonic pressure 


\section{Materials and Methods}

Preparation of samples: A plain weave wool fabric was procured from the local market of Ludhiana, Punjab. Roots of Ratanjot plant were collected from Herbal garden of Punjab Agricultural University campus. The root parts were dried under the sun and finely ground into powder form. Four types of mordants namely Amla, babool gum powder (Natural mordants) and Alum and tannic acid (Synthetic mordants) were used. Analytical grade urea, sodium chloride, sodium carbonate and acetic acid were used in the experiments.

Optimisation of dyeing parameters: Experiments were conducted for optimizing ultrasonic dyeing and mordanting conditions of wool with roots of ratanjot dye using four different natural and synthetic mordants. The conditions namely - dye extraction time $(15,30,45,60$ minutes), dye extraction temperature $\left(30,45\right.$ and $\left.60{ }^{\circ} \mathrm{C}\right)$, dyeing concentration $(1,2,3,4$ and $5 \mathrm{~g} / \mathrm{g})$, dyeing time (30, $45,60,75$ and 90 minutes), dyeing $\mathrm{pH}$ (4- 8) and dyeing temperature $\left(30,45\right.$ and $\left.60{ }^{\circ} \mathrm{C}\right)$ were optimized. Mordant concentration of $0.1,0.2,0.3$, 0.4 and $0.5 \mathrm{gm}$ of amla and babool mordants were mordanted simultaneously at optimum dyeing $\mathrm{pH}$, for optimum time at optimum temperature. The concentrations of alum were 5, 10, 15, 20 and $25 \mathrm{gm} / 100 \mathrm{~g}$ of fabric. The concentrations of tannic acid were 1, 2, 3, 4 and 5 per $100 \mathrm{~g}$ of fabric.

Final dyeing of wool fabric by using Conventional and Ultrasonic dyeing methods: Conventional dye extraction was carried out as described by Bains et al. (2002). The optimized dyeing conditions for conventional dyeing technique were dye concentration of $3 \mathrm{~g} / \mathrm{g}$ of fabric, dyeing $\mathrm{pH} 7$, dyeing time of $90 \mathrm{~min}$ and $100^{\circ} \mathrm{C}$ dyeing temperature. The optimum mordant concentration of of amla, babool, alum and tannic acid were $0.5,0.2,15$ and $4 \mathrm{~g} / \mathrm{g}$ of fabric respectively. The dye solution was poured in the ultrasonic cleaner bath, keeping the Material to liquor ratio (MLR) of 1:250. A pre-soaked wool fabric was immersed into the dye solution and subjected to ultrasound at optimized temperature for optimized time. The simultaneous mordanting method was performed at optimized mordant concentration. After dyeing, the baths were allowed to cool down for some time to avoid sudden change during rinsing. The samples were taken out, washed in mild detergent solution and rinsed in tap water to remove unfixed dye material. After thoroughly rinsing, the samples were finally dried in shade. The dyeing with ultrasound was carried out at $220 \mathrm{~V} / 50 \mathrm{~Hz}$.

Evaluation of colour strength: The colour strength $(\mathrm{K} / \mathrm{S})$ of dyed fabric is a measure of dye concentration on the fabrics. The colour strength expressed as the $\mathrm{K} / \mathrm{S}$ value in the wavelength range $400-700 \mathrm{~nm}$ at $10 \mathrm{~nm}$ intervals within the visible spectrum was calculated by the following Kulbelka - Munk equation:

$\mathrm{K} / \mathrm{S}=(1-\mathrm{R})^{2} / 2 \mathrm{R}$

Where "R" is the reflectance at the wavelength of maximum absorption, " $\mathrm{K}$ " is absorption coefficient and " $\mathrm{S}$ " is the scattering coefficient. The higher the K/S value, the greater is the dye uptake, resulting in better colour yield.

Evaluation of CIE Lab value: CIE Lab (L*, a*, $\left.b^{*}\right)$ values of the dyed samples were recorded with illuminant $\mathrm{D} 65 / 10^{\circ}$ observer using Colorflex Hunter Lab. The measurement was replicated four times for each sample. Colour coordinates CIE $L^{*} a^{*} b^{*}$ were determined to define the properties of color on dyed fabric. CIE $L^{*} a^{*} b^{*}$ values were used to evaluate the lightness, red/green, and blue/yellow characteristics of the dyed samples. $\mathrm{L}^{*}$ is corresponding to the brightness $(100=$ white, $0=$ black), $\mathrm{a}^{*}$ is corresponding to the $\mathrm{red} /$ green coordinate (positive sign $=$ red, negative $\operatorname{sign}=$ green $)$, and $b^{*}$ is corresponding to the yellow/blue coordinate (positive sign=yellow, negative $\operatorname{sign}=b l u e)$. From the $L^{*}, a^{*}$, and $b^{*}$ coordinates, chroma $\left(\mathrm{C}^{*}\right)$ values were calculated by using the following equation:

$\mathrm{C} *=\sqrt{ }\left(\mathrm{a}^{* 2}+\mathrm{b}^{* 2}\right)$

Chroma measures the intensity or saturation of the colourant

Evaluation of Colour fastness: The light, wash, rubbing and perspiration fastness values of all dyed samples were determined by Digital light fastness tester, Launderometer, Crockmeter and Perspirometer, tested according to ISO test methods.

Statistical analysis: The optical density and K/S values of each dyeing condition were evaluated by analysis of mean and each treatment was replicated 
three times. The standard error of the difference SED $( \pm)$ was calculated for each mordant.

\section{Results and Discussion}

Various experiments were carried out to compare the conventional and ultrasonic methods for dyeing of wool fabric in terms of dye uptake and colour fastness properties.

Optimized dyeing conditions: Fig.3. indicates that the value of optical density gradually increased with increase in extraction time of dye. It was also observed that the optical density was higher at dye extraction time of 60 minutes. Therefore, 60 minutes is taken as the optimum dye extraction time. The results obtained from Figure 4 revealed that optical density of dye solution increased with increase in extraction time. It was observed that the optical density was maximum at $60^{\circ} \mathrm{C}$. From the Fig.5, it is clear that dye absorption increased when the dye material was increased from 1 to $2 \mathrm{~g} / \mathrm{g}$ of wool fabric, but decrease in dye absorption with increase in the dye concentration from 3 to $5 \mathrm{~g} / 100$ $\mathrm{g}$ of wool. Therefore, $2 \mathrm{~g} / \mathrm{g}$ was the optimum dye concentration of wool. K/S values for different dyeing $\mathrm{pH}$ furnished in Fig.6 revealed that the dye absorption increased from dyeing $\mathrm{pH}$ from 4 to 5 . But there was gradual decrease in the dye absorption when dyeing $\mathrm{pH}$ increased from 6 to 8 . The maximum $\mathrm{K} / \mathrm{S}$ value was found at dyeing $\mathrm{pH}$ of 5. It was also observed that the dye absorption increased as the dyeing temperature increased as shown in Fig.7. Dye absorption was maximum at $60^{\circ} \mathrm{C}$ and considered as optimum dyeing temperature. It could be envisaged from the Fig. 8 that initially the values of $\mathrm{K} / \mathrm{S}$ increased when dyeing time was increased from 30 to 75 minutes. The K/S values were decreased when the dyeing time increase from 75 to 90 minutes. The colour strength was found to be maximum at dyeing time of 75 minutes. Therefore, the maximum dyeability was found at dye extraction time 60 minutes and dye extraction temperature $60^{\circ} \mathrm{C}$. And, the maximum dye was absorbed at dye material concentration $2 \mathrm{~g} / \mathrm{g}$ of wool, dyeing $\mathrm{pH} 5$, dyeing temperature $60^{\circ} \mathrm{C}$ and dyeing time 75 minutes.

Interestingly, when compared, the optimized dyeing conditions of ultrasonic and conventional dyeing methods, it was found that there was reduction of dye concentration requirement, dyeing time and dyeing temperature by using ultrasonic waves since the optimized dye concentration, dyeing time and dyeing temperature of conventional dyeing method on wool were $3 \mathrm{~g} / \mathrm{g}$ of fabric, 90 minutes and $100^{\circ} \mathrm{C}$ respectively. Therefore, ultrasonic dyeing method saves energy, time and amount of dye requirement. The optimum mordant concentration values have been presented in table 1 . The optimum value for amla was found to be $0.4 \mathrm{~g} / \mathrm{g}$, whereas, for babool, it was $0.5 \mathrm{~g} / \mathrm{g}$. For alum it was $15 \mathrm{~g} / \mathrm{g}$ and $4 \mathrm{~g} / \mathrm{g}$ for tannic acid. Tannic acid mordanted samples showed maximum K/S values followed by amla, babool and alum.

Evaluation of Colour strength: The colour strength (K/S values) of wool fabric using both conventional and ultrasonic dyeing methods was shown in Fig. 9. Comparing the conventional and ultrasonic methods, the colour strength value obtained by ultrasonic dyeing method was higher than with conventional method. This was due to the formation of microscopic bubbles, or cavitations by the ultrasonic waves in the liquid system. When these bubbles are collapsed, they generate tiny but powerful shock waves. The release of micro bubbles and shock waves led to promote the action and binding between the dye particles and wool fibre. Likewise, one study also observed that the ultrasonic dyed samples with Drimerene Blue ClBR and Drimarene Red Cl-5B improved its colour strength than the conventional dyed samples (Syed et al., 2013). It was also observed that $\mathrm{K} / \mathrm{S}$ value of unmordanted sample was more than the sample mordanted with the alum on wool. Mansour and Heffernan (2011) also found that the value of colour strength of silk fabric dyed with sticta coronata lichen declined when mordanted with $10 \mathrm{~g}$ of alum in the presence of ultrasound. The reason may be due to formation of cluster/ aggregation of alum solution that rupture the interaction of structure thus hinders formation of bond between the metal ions and dye molecules under the ultrasonic energy. Maximum colour strength was found to be in sample mordanted with tannic acid on wool.

Evaluation of CIE Lab Values: CIE Lab values for dyed fabrics with Ratanjot in both conventional and ultrasonic methods with different mordants were given in Table 2 . The results revealed that the $\mathrm{L}^{*}$ value of all the ultrasonic dyed samples were 


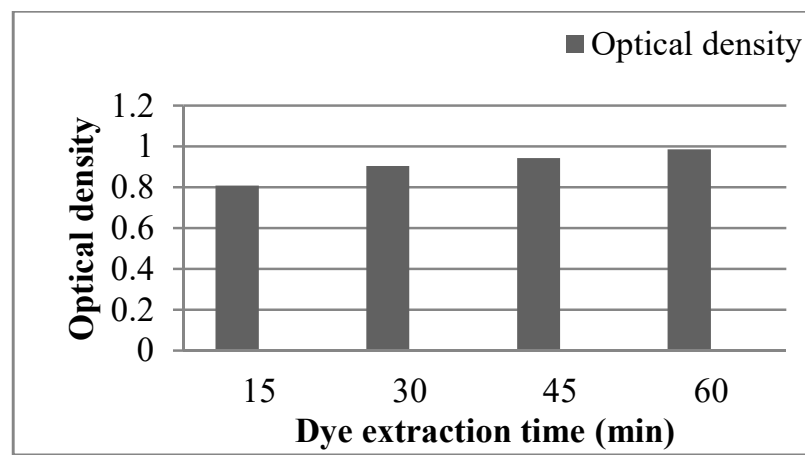

Figure 3: Optimization of dye extraction time of Ratanjot dye

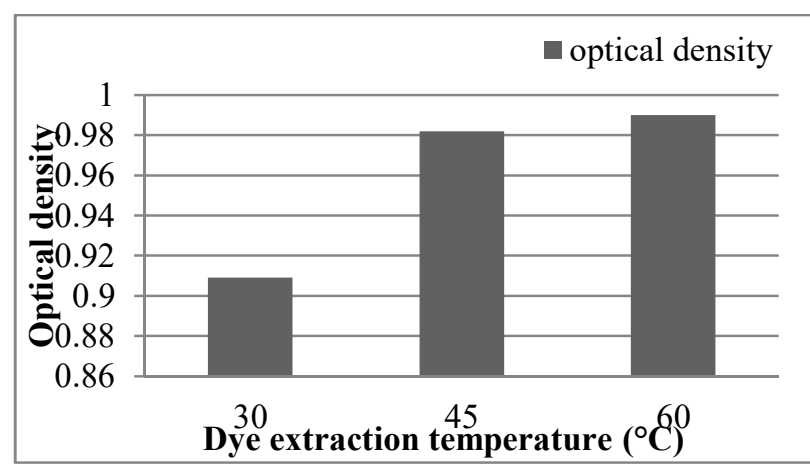

Figure 4: Optimization of dye extraction temperature of Ratanjot dye

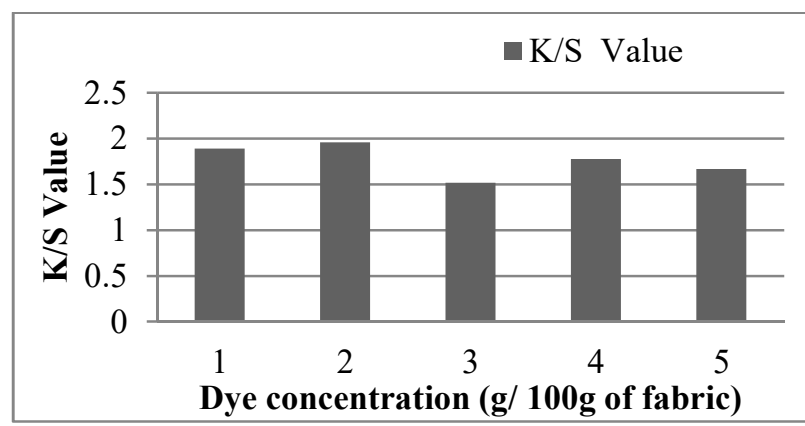

Figure 5: Optimization of dye concentrations of Ratanjot dye

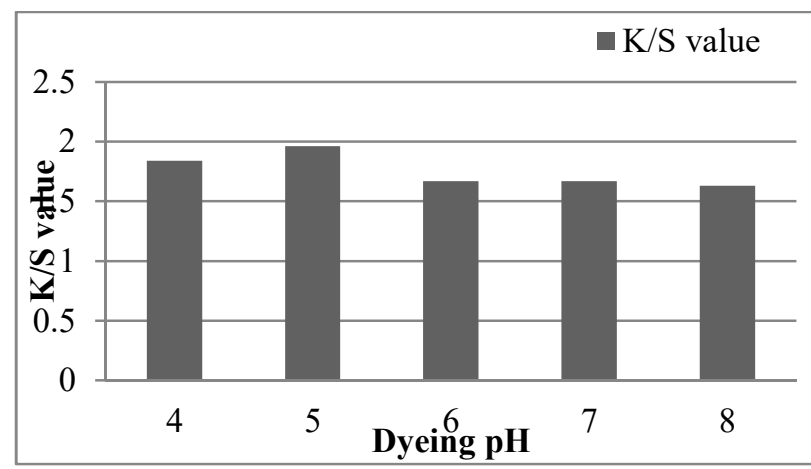

Figure 6: Optimization of dyeing pH of Ratanjot dye

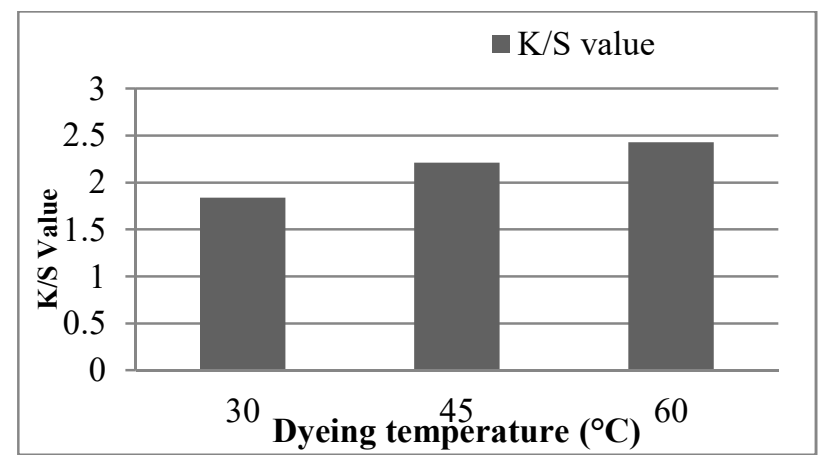

Figure 7: Optimization of dyeing temperature of Ratanjot dye

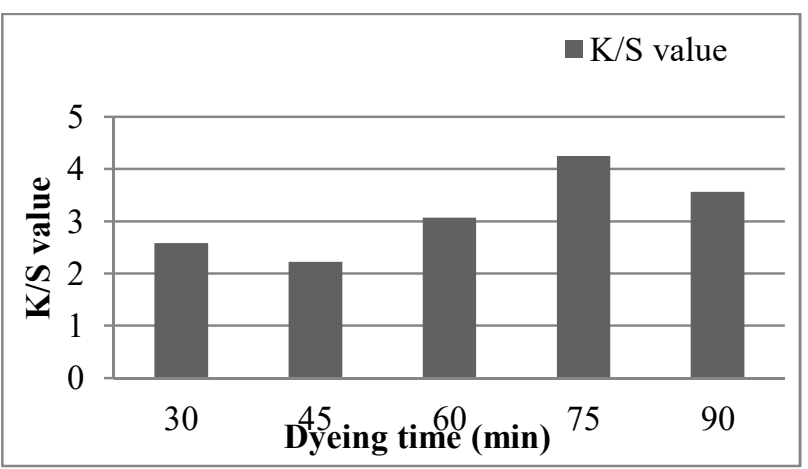

Figure 8: Optimization of dyeing time of Ratanjot dye

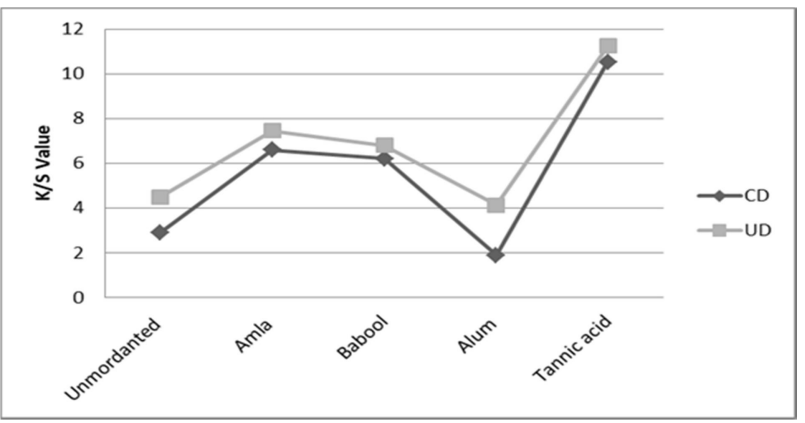

$\mathrm{CD}=$ Conventional dyed sample, $\mathrm{UD}=$ Ultrasonic dyed sample

Figure 9: Comparison of the K/S value of dyed wool fabric using both conventional and ultrasonic dyeing method

less than the conventional dyed samples, which indicate that the ultrasonic dyed samples gave darker shades. The higher and positive a* value of the all the ultrasonic dyed samples showed that the samples were redder as compared to conventional dyed samples. The ultrasonic samples mordanted with amla were redder, followed by babool, unmordanted, alum and tannic acid samples. In 
Devi et al.

Table 1: Optimization of mordant concentrations for Ratanjot dye on wool

\begin{tabular}{|l|l|l|l|l|l|l|l|}
\hline $\begin{array}{l}\text { Mordant } \\
\text { concentration } \\
\text { g/100g wool of } \\
\text { Amla }\end{array}$ & $\begin{array}{l}\text { K/S } \\
\text { value }\end{array}$ & $\begin{array}{l}\text { Mordant } \\
\text { concentration } \\
\text { g/100g wool of } \\
\text { Babool }\end{array}$ & $\begin{array}{l}\text { K/S } \\
\text { value }\end{array}$ & $\begin{array}{l}\text { Mordant } \\
\text { concentration } \\
\text { g/100g wool of } \\
\text { Alum }\end{array}$ & $\begin{array}{l}\text { K/S } \\
\text { value }\end{array}$ & $\begin{array}{l}\text { Mordant } \\
\text { concentration } \\
\text { g/100g wool of } \\
\text { Tannic acid }\end{array}$ & $\begin{array}{l}\text { K/S } \\
\text { value }\end{array}$ \\
\hline 0.1 & 6.03 & 0.1 & 4.99 & 5 & 3.77 & 1.0 & 8.17 \\
\hline 0.2 & 6.41 & 0.2 & 5.02 & 10 & 4.01 & 2.0 & 8.70 \\
\hline 0.3 & 6.80 & 0.3 & 5.86 & 15 & 4.12 & 3.0 & 9.26 \\
\hline 0.4 & 7.22 & 0.4 & 6.40 & 20 & 3.89 & 4.0 & 10.53 \\
\hline 0.5 & 6.80 & 0.5 & 6.60 & 25 & 3.56 & 5.0 & 9.87 \\
\hline
\end{tabular}

Table 2: Chromaticity values of the dyed wool fabric

\begin{tabular}{|c|c|c|c|c|c|c|c|c|}
\hline \multirow[t]{2}{*}{ Samples } & \multicolumn{2}{|l|}{$\mathbf{L}^{*}$} & \multicolumn{2}{|l|}{$a^{*}$} & \multicolumn{2}{|l|}{$\mathbf{b}^{*}$} & \multicolumn{2}{|l|}{$C^{*}$} \\
\hline & CD & U D & C D & U D & C D & U D & C D & U D \\
\hline Unmordanted & 69.63 & 68.22 & 3.44 & 7.19 & 15.70 & 14.05 & 16.07 & 15.78 \\
\hline Amla & 73.59 & 71.58 & 8.33 & 9.82 & 28.93 & 30.87 & 9.91 & 32.39 \\
\hline Babool & 52.14 & 43.56 & 7.78 & 9.35 & 18.30 & 17.07 & 19.88 & 19.46 \\
\hline Alum & 57.90 & 51.00 & 2.69 & 4.33 & 16.92 & 12.21 & 17.13 & 12.95 \\
\hline Tannic Acid & 46.64 & 41.98 & 1.35 & 1.79 & 6.36 & 8.34 & 6.50 & 8.60 \\
\hline
\end{tabular}

$\mathbf{C D}=$ Conventional Dyed sample, $\mathbf{U D}=$ Ultrasonic Dyed sample, $\mathbf{L}^{*}=$ Lighter/ darker, $\mathbf{a}^{*}=$ Redder/ greener, $\mathbf{b}^{*}=\mathrm{Yellower} /$ bluer, $C^{*}=$ Intensity/ saturation of the colorant

Table 3: Colour fastness grades of conventional and ultrasonic wool dyed using Ratanjot dye

\begin{tabular}{|c|c|c|c|c|c|c|c|c|c|c|c|c|c|c|}
\hline \multirow{4}{*}{$\begin{array}{l}\text { Samples } \\
\text { Unmordanted }\end{array}$} & \multirow{4}{*}{$\begin{array}{l}\text { Light } \\
\text { fastness } \\
\text { grades }\end{array}$} & \multicolumn{3}{|c|}{$\begin{array}{l}\text { Washing } \\
\text { fastness grades }\end{array}$} & \multicolumn{4}{|c|}{$\begin{array}{l}\text { Rubbing fastness } \\
\text { grades }\end{array}$} & \multicolumn{6}{|c|}{ Perspiration fastness grades } \\
\hline & & \multirow[t]{3}{*}{$\mathrm{CC}$} & \multicolumn{2}{|c|}{ CS } & \multicolumn{2}{|c|}{ Dry } & \multicolumn{2}{|c|}{ Wet } & \multicolumn{3}{|c|}{ Acidic } & \multicolumn{3}{|c|}{ Alkaline } \\
\hline & & & \multirow[t]{2}{*}{$\mathrm{C}$} & \multirow[t]{2}{*}{$\mathrm{W}$} & \multirow[t]{2}{*}{$\mathrm{CC}$} & \multirow[t]{2}{*}{$\mathrm{CS}$} & \multirow[t]{2}{*}{$\mathrm{CC}$} & \multirow[t]{2}{*}{$\mathrm{CS}$} & \multirow[t]{2}{*}{$\mathrm{CC}$} & \multicolumn{2}{|c|}{$\mathrm{CS}$} & \multirow[t]{2}{*}{$\mathrm{CC}$} & \multicolumn{2}{|c|}{$\mathrm{CS}$} \\
\hline & & & & & & & & & & $\mathrm{C}$ & $\mathrm{W}$ & & $\mathrm{C}$ & $\mathrm{W}$ \\
\hline CDS & 2 & $4 / 5$ & 5 & $4 / 5$ & 5 & 5 & 5 & $4 / 5$ & 4 & 5 & 5 & 5 & 5 & 4 \\
\hline UDS & $2 / 3$ & $4 / 5$ & 5 & 5 & 5 & 5 & 5 & 5 & 5 & 5 & 5 & 5 & 5 & 5 \\
\hline \multicolumn{15}{|l|}{ Amla } \\
\hline CDS & 2 & 5 & 5 & 5 & 5 & 5 & 5 & 4 & 5 & 5 & 5 & 5 & 5 & 5 \\
\hline UDS & 2 & 5 & 5 & 5 & 5 & 5 & 5 & $4 / 5$ & 5 & 5 & 5 & 5 & 5 & 5 \\
\hline \multicolumn{15}{|l|}{ Babool } \\
\hline CDS & $2 / 3$ & $4 / 5$ & 5 & 5 & 5 & 5 & 5 & $4 / 5$ & 5 & 5 & 5 & 4 & 5 & 4 \\
\hline UDS & 3 & 5 & 5 & 5 & 5 & 5 & 5 & 5 & 5 & 5 & 5 & 5 & 5 & 5 \\
\hline \multicolumn{15}{|l|}{ Alum } \\
\hline CDS & 2 & 3 & 4 & 5 & 5 & 4 & 5 & 3 & 3 & 5 & 5 & 4 & 5 & 5 \\
\hline UDS & 2 & 4 & $4 / 5$ & 5 & 5 & $4 / 5$ & 5 & 4 & 4 & 5 & 5 & 5 & 5 & 5 \\
\hline \multicolumn{15}{|l|}{ Tannic acid } \\
\hline CDS & 2 & 3 & 4 & 5 & 5 & 4 & $4 / 5$ & 4 & 5 & 5 & 4 & 5 & 5 & 4 \\
\hline UDS & $2 / 3$ & 4 & $4 / 5$ & 5 & 5 & $4 / 5$ & 5 & 4 & 5 & 5 & 5 & 5 & 5 & 4 \\
\hline
\end{tabular}

$\mathrm{C}=$ Cotton, $\mathrm{W}=$ Wool, $\mathbf{C C}=$ Color Change, $\mathbf{C S}=$ Color Staining, $\mathrm{CDS}=$ Conventional Dyed Sample, $\mathrm{UDS}=$ Ultrasonic Dyed Sample

both the techniques, the $a^{*}$ value of samples compared to their conventional dyed sample mordanted with alum and tannic acid showed light whereas, lower $b^{*}$ values of ultrasonic dyed red as compared to unmordanted (control) sample. unmordanted, mordanted samples with babool and It is clear from the table 2. that the higher $b^{*}$ value alum indicated that they have light yellow colour as of ultrasonic dyed samples mordanted with amla compared their conventional dyed samples. The $\mathrm{C}^{*}$ and tannic acid samples showed more yellowish as values of conventional dyed samples were higher 
than the samples obtained by ultrasonic waves except the amla and tannic acid mordanted samples, which indicates that the samples obtained by ultrasonic waves are more saturated as compared to conventional boiling.

Evaluation of colour fastness properties: The light, washing, rubbing and perspiration fastness grades of wool samples dyed with Ratanjot dye have been presented in the table 3 .

The light fastness properties of conventional dyed samples was 2, indicated poor and improved to fair when the sample dyed by using ultrasonic dyeing technique. The washing fastness grades in terms of colour change were improved because of ultrasonic wave. No staining was observed on wool for both conventional and ultrasonic dyed sample except for unmordanted sample. Therefore, ultrasonic dyed samples have better washing fastness properties as compared to conventional dyed samples. In ultrasonic dyeing techniques, dye molecules are not fixed on the fibre surface but it reacted with the the fibre surface. Similarly, the rubbing fastness and perspiration grade of conventional dyed was improved in ultrasonic dye samples. Another study also found that rubbing fastness properties of cotton,silk and wool fabric give the better result when dyed with Malus sikkimensis by using ultrasonic dyeing techniques as compared to conventional dyeing techniques (Vankar et al., 2009).

\section{Conclusion}

In this study, the dye extraction and dyeing conditions of wool fabric with ratanjot natural dye were optimised. Based on the optical density and $\mathrm{K} / \mathrm{S}$ values, the optimum dye extraction conditions of ultrasonic dyeing methods were- extraction time

\section{References}

Arora, A., Gulrajani, M. L. and Gupta, D. 2009. Identification and Characterization of Ratanjot (Arnebia nobilis reichb.f.). Natural Product Radiance, 8:142-145.

Bains, S., Singh, O. P., Goraya, G. and Kang, M. 2002. Dyeing of Cotton with Goldendrop (Onosma echoides) Dye. Journal of Textile Association, 64:183-186.

Chattopadhyaya, S. N., Pan, N. C. and Khan, A. 2018. Printing of Jute Fabric with Natural Dyes Extracted from Manjistha, Annatto and Ratanjot. Indian Journal of Fibre and Textile Research, 43: 352-356.
$60 \mathrm{~min}$ and extraction temperature $60^{\circ} \mathrm{C}$ while the optimized dyeing parameters were- dyeing temperature $60^{\circ} \mathrm{C}$, dye concentration $2 \mathrm{~g} / \mathrm{g}$, dyeing time $75 \mathrm{~min}$ and dyeing $\mathrm{pH}$ 5. Interestingly, the use of ultrasonic wave in the dyeing process was found to be significant improvement in the colour strength $(\mathrm{K} / \mathrm{S})$ and colour fastness properties as compared to conventional heating method. In addition to advantage of dye absorption and colour fastness, fabrics dyed by using ultrasonic dyeing method showed a deeper shade colour and good colour intensity than conventional dyeing method. Moreover, the textile dyeing industry has long been struggling to cope with high energy costs, rapid technological changes and the need for a faster delivery time. The effective management of ultrasonic technology can reduce the energy costs and improve productivity. Though the initial capital cost of installing ultrasonic dyeing machines would be high but it will ultimately save energy by dyeing at low costs. In conventional dyeing, high dyeing temperatures are maintained for which lot of energy is used. Moreover, many synthetic mordants and auxillaries are required in conventional dyeing which not only adds to the cost but also pollutes the environment. In ultrasonic dyeing, there will be reduced consumption of auxiliary chemicals which will lower the processing costs and also lessen the processing time. Hence, it will be a win-win situation for both the manufacturer and the environment.

\section{Acknowledgement}

The authors are grateful to the Department of Apparel and Textile Science, Punjab Agricultural University, Ludhiana, Punjab for provision of research facilities and support.

Chattopadhyaya, S. N., Pan, N. C., Roy, A. K., Sexena, S. and Khan. A. 2013. Development of Natural Dyed Jute Fabric with Improved Colour Yield and UV Protection Characteristics. Journal of Textile Institutions, 104: 808818.

Gupta, L. and Saini, H. K. 2018. Optimization of Dyeing Parameters of Angora Wool with Natural Dye from Root of Ratanjot (Onosma echioides). International Journal of Applied Home Science, 5: 94-101.

Kamel, M. M., El -Zawahry, N. S. E., Ahmed, and Abdelghaffar, F. 2011. Ultrasonic Dyeing of Cationized 
Devi et al.

Cotton Fabric with Natural Dye, Part 2: Cationization of Cotton using Quat 188. Industrial Crop Products, $34: 1410-1417$

Mansour, H.cF. and Haffernan, S. 2011. Environmental Aspects on Dyeing Silk Fabric with Sticta coronate lichen using Ultrasonic Energy and Mild Mordants. Clean Technologies and Environmental Policy, 13:207-213.

Mukherjee, S. and Kanakarajan, S. 2017. Extraction, Optimisation and Dyeing of Silk Yarn using Natural Dye from cosmos sp. International Journal of Development Research, 7:13865-13871.

Paisan, K., Aroonsiri, S. and Nontalee, C. 2002. Thermodynamics of Adsorption of Laccaic acid on Silk. Dyes and Pigments, 53:179-185.

Parvinzadeh, M., Memari, N., Shaver, M., Katozian, B., Ahmadi, S. and Ziadi, I. 2009. Influence of Ultrasonic Waves on the Processing of Cotton with Cationic Softener. Journal of Surfactants and Detergents, 13:135-141.

Prabhu, K. H. and Bhute, A. S. 2012. Plant Based Natural Dyes and Mordants: A Review. Journal of Natural Product and Plant Resources, 2:649-664.

Rahman, N. A. A., Tumin, S. M. and Tajuddin. R. 2013. Optimization of Ultrasonic Extraction Method of Natural Dyes from Xylocarpus Moluccensis. International Journal of Bioscience, Biochemistry Bioinformatics, 3: 53-55.
Saravanan, P. and Chandramohan, G. 2011. Dyeing of Silk with Eco-friendly Natural Dye obtained from Barks of Ficus religiosa. Universal Journal of Environmental Research and Technology, 1:268-273.

Syed, U., Jhatial, R. A. and Peerzada, M. H. 2013. Dyeing of Organic Cotton Fabric using Ultrasonic Dyeing Technique. 14th AUTEX World Textile Conferences, Mehran University of Engineering and Technology, Pakistan. Pp. $1-7$.

Udrescu, C., Ferrero, F. and Periolatto, M. 2014. Ultrasoundassisted Dyeing of Cellulose acetate. Ultrasonic Sonochemistry, 21: 1477-1481.

Vankar, P.S., Shanker, R., Dixit, S. and Mahanta, D. 2009. Sonicator Dyeing of Cotton, Wool and Silk with Leaves Extract. Journal of Textile and Apparel, Technology and Management, 6: 1-11.

Yusuf, M., Mohammad, F., Shabbir, M. and Khan, M. A. 2016. Eco-dyeing of Wool with Rubia cordifolia Root Extract: Assessment of the Effect of Acacia catechu as Biomordant on Color and Fastness Properties. Textiles and Clothing Sustainability, 2:1-9.

Yusuf, M., Shabbir, M. and Mohammad, F. 2017. Natural Colorants: Historical, Processing and Sustainable Prospects. Natural Products and Bioprospecting, 7: 125145. 